\title{
El espiritu libre o la ligereza creadora
}

\author{
VIRGINIA MARIBEL CANO \\ Universidad de Buenos Aires
}

En la primavera de 1886 Nietzsche dedicaría Humano, demasiado humano a aquellos espíritus libres que le habrían propiciado compañía cuando requería de ella. Falto de amigos y en estado de aislamiento, habría surgido la necesidad de la invención de estas almas también solitarias que constituyen uno de los caminos ${ }^{1}$ que atraviesa el pensamiento nietzscheano. Camino éste que pretendemos recorrer para pensar una de las relaciones más importantes que plantea el pensamiento nietzscheano: el vínculo entre la crítica y la creación.

A partir de la metáfora nietzscheana del espíritu libre ${ }^{2}$ nos proponemos, entonces, recorrer dos sendas: aquella de raigambre ilustrada que pone el

\footnotetext{
${ }^{1}$ La noción de 'camino' que utilizamos aquí es la propuesta por Paolo D'Iorio en su artículo «Système, phases, chemins, strates. Modèles et outils pour l'étude d'une philosophie en devenir", en D'Iorio, P. y Olivier, P. (eds), Philosophie de l'esprit libre. Études sur la genèse de Choses humaines, trop humaines, Paris: Éditions Rue d'Ulm/Presses de l'École normale supérieure, 2004, pp. 21-36. Allí explica: «Nous pensons que la notion de "chemin", génétique, chronologique ou thématique, pourra mieux répondre à la volonté de comprendre et $\mathrm{d}$ 'analyser une philosophie en devenir. [...] La possibilité de rassembler et de disposer côte à côte les notes qui s'insèrent dans une ligne thématique déterminée favoriserait grandement l'étude philosophie de la pensée de Nietzsche. Sans pour autant forcer et figer sa pensée dans un ordre thématique donné une fois pour toutes, comme cela arrive souvent dans des montages arbitraires de notes posthumes qui [...] finissent trop souvent par passer pour de véritables œuvres de Nietzsche» ibid., pp. 35-36. La noción de 'camino' nos obliga a abandonar la interpretación del pensamiento nietzscheano a partir de los conceptos de fases y sistema.

${ }^{2}$ Es pertinente destacar que usaremos como términos que aluden a la misma figura las siguientes palabras: freier Geist (espíritu libre), Freigeist- Freidenker (librepensador) y freier Denker (pensador libre). A pesar de ello, Nietzsche no siempre los usa indistintamente. Cf. JGB $\$ 44$, KSA V 60-63. Si bien en ocasiones como ésta Nietzsche contrapone a los espíritus libres con los librepensadores, la mayoría de las veces estos términos se refieren a una misma figura, al espíritu liviano que se distingue del rebaño y el espíritu de pesadez. Teniendo en cuenta esto último, y siempre que ello no genere problemas interpretativos, a continuación se tomarán de modo indistinto los términos antes aludidos.
} 
acento en el carácter crítico de la liberación del espíritu, y aquella otra que se centra en el aspecto creativo de la libertad. El olvido será la pieza clave de nuestra interpretación, pues el mismo se mostrará como la fuerza que une en un ámbito de integración el 'no' y el 's'.'

\section{El espíritu libre COMO CONCEPTO RELATIVO}

El espíritu libre es la figura ilustrada que encarna el espíritu crítico propio del siglo de las luces ${ }^{3}$. La importancia concedida a la crítica es quizás el aspecto más ilustrado que hemos de encontrar en el pensamiento de Nietzsche, esa disposición a pensar más allá de toda autoridad y de toda tradición filosófica. Pensemos en el distanciamiento de Nietzsche respecto de la tutela de Wagner y de Schopenhauer, tutela que signaría todos sus escritos juveniles. Pensemos también en un Nietzsche que decide empuñar el martillo y arremeter contra la metafísica, la moral, la religión y la cultura de su época. Es a partir de la comprensión de este impulso ilustrado que entendemos por qué «[...] odia el librepensador todas las habituaciones y reglas, todo lo duradero y definitivo, por lo cual una y otra vez desgarra, con dolor, la red en torno a sí, pese a que como consecuencia de ello sufrirá innumerables heridas grandes y pequeñas, [...].»4. Es justamente por su disposición a pensar más allá de la tutela de la tradición que el espíritu libre odia las estructuras sedimentadas.

El librepensador se caracteriza, entonces, por su postura crítica que se traduce en su apartarse de lo tradicional, en su carácter de excepción y no de regla. A la hora de analizar esta posición deconstructiva ${ }^{5}$ que representa el espíritu libre podemos seguir una de las vías que nos propone el propio Nietzsche y que consiste en pensar al espíritu libre como un "concepto relativo», en conjunción con el de "espíritu gregario».

El espíritu gregario es caracterizado en base a su "fortaleza de carácter», es decir, por sus "pocos motivos, acción enérgica y buena conciencia» ${ }^{6}$. Su fuerza radica en su habituación, en la repetición de la tradición, en su espíritu

\footnotetext{
${ }^{3}$ Para un análisis de la influencia de la ilustración en Nietzsche cf. Kessler, M., «La critique des idéaux dans Choses humaines, trop humaines», en D'Iorio, P. y Olivier, P. (eds), op. cit, pp. 143-151, y Chaves, E., "Lessing, un esprit libre. Sur l'aphorisme 103 de Voyageur et son ombre», en ibid., pp. 113-127.

${ }^{4}$ MA I $\$ 427$, KSA II 280 (HH I tr. A. Brotons Muńoz, Madrid: Akal, 1996, p. 211).

${ }^{5}$ Más allá de la connotación derrideana que supone el término, utilizamos "deconstrucción" para referirnos a la tarea nietzscheana de desmontaje de los conceptos de la metafísica tradicional.

${ }^{6}$ Ibid., $\$ 228$, p. 392. (HH I, p. 154).
} 
de rebańo. De modo que «al fuerte de carácter le falta el conocimiento de las muchas posibilidades y orientaciones de la acción ${ }^{7}$, su intelecto es servil y su espíritu pesado. En el mundo del mercado reina la homogeneidad, «todos quieren lo mismo, todos son iguales: quien tiene sentimientos distintos marcha al manicomio ${ }^{8}$. De modo que la fortaleza del espíritu gregario radica en el desconocimiento de la pluralidad de perspectivas, en la seguridad de su pertenencia al reino de la mismidad en el que el peligro de las posibilidades del diferir no se hace presente. Unilateralidad en la visión de mundo y petrificación de sentidos parecen ser las marcas distintivas de este espíritu pesado?

Frente a la fortaleza gregaria, la debilidad parece ser lo propio del espíritu libre. De hecho, «en comparación con quien tiene la tradición de su parte y no precisa de razones para su conducta, el librepensador siempre es débil, sobre todo en la acción; pues conoce demasiados motivos y puntos de vista» ${ }^{10}$. Privado de la seguridad de la habituación, de la unilateralidad de perspectiva, y arrojado a la multiplicidad de puntos de vistas, el espíritu libre se nos presenta, comparativamente con el espíritu gregario, como débil.

Y sin embargo, el espíritu libre es un "espíritu fuerte». Y es aquí donde parece contribuir a la elucidación de esta figura la idea nietzscheana de "concepto relativo". Desde la perspectiva del rebańo, de la fortaleza y seguridad que lleva implícita toda homogeneidad, en su despegarse de las tradiciones, el espíritu libre parece débil. Pero es paradójicamente en esta misma independencia donde radica su fortaleza. Sentencia Nietzsche en un fragmento póstumo respecto al fuerte de voluntad que «es independiente de los demás, por tanto libre (en cuanto dependiente de sí). El no libre, débil, no es lo bastante dependiente de sí, muy dependiente por tanto de los demás.» ${ }^{11} \mathrm{El}$ verdaderamente débil es el espíritu gregario, pues depende siempre de los demás. El hombre gregario requiere siempre de los sentidos e interpretaciones ya dados, de una tradición que resguarde su modo de vida. Es por ello que el hombre del mercado perece en la soledad, el rebańo sólo existe como tal. Y aquí se asienta su carácter de no-libre. Desde esta perspectiva, el fuerte es el espíritu libre que no depende de la tutela de la tradición, y que únicamente depende de sí mismo. En su independencia está su fuerza y también su soledad.

${ }^{7}$ Ibid.

${ }^{8}$ Za, "Zarathustra’s Vorrede”, \$5, KSA IV 20 (Za ed. A. Sánchez Pascual, Barcelona: Altaya, 1997, p. 39).

${ }^{9}$ Cf. MA I, $\$ \$ 227-228$ (HH I pp. 192-193).

${ }^{10}$ Ibid, $\$ 230$, p. 193. (HH I pp. 154-155).

${ }^{11}$ KSA VIII 617: 47[1] (HH II p. 333). 
La libertad de espíritu implica abandonar el reparo de la mismidad. Es por ello que es «[...] cosa de muy pocos ser independiente:- éste es un privilegio de los fuertes. Y quien intenta serlo sin tener necesidad, aunque tenga todo el derecho, demuestra que probablemente no sólo es fuerte, sino temerario hasta el extremo. Se introduce en un laberinto, multiplica por mil los peligros que ya la vida trae consigo de por sí; de éstos no es el menor el que nadie vea con sus ojos cómo y en donde él mismo se extravía, se aísla [...]»» $»^{12}$. El espíritu fuerte está condenado a la soledad ${ }^{13}$ y el aislamiento. Con sus dientes de dragón ha desgarrado la telaraña que tejen los hilos de la tradición, y por ello se ha extraviado. Volando solo puede ahora emprender una «peregrinación al extranjero", hacia el futuro, pero siempre en soledad, en el exilio.

\section{LA LIGEREZA ESPIRITUAL}

La experiencia del exilio propia de la liberación del espíritu puede ser comprendida en relación a lo que Nietzsche denomina «ligereza» espiritual. Los espíritus libres son los dioses de la vida liviana ${ }^{14}$ que luchan contra las ataduras del espíritu gregario. Para el espíritu libre, enemigo mortal del espíritu de pesadez, «la vida se hace más liviana y agradable mediante una liberación intransigente del espíritu que un buen día, zarandea todas las representaciones que hacen la vida tan gravosa, tan intolerable, de modo que para tener la alegría de esta desgravación, se prefiere la vida más simple, la que nos posibilita esta alegría» ${ }^{15}$. La liberación representa una alegre liviandad para el espíritu.

Sin embargo, para acceder a la «alegría de esta desgravación», el espíritu libre debe experimentar una larga agonía. El proceso de distanciamiento y crítica por medio del cual se deshace de las representaciones que vuelven la vida gravosa es descrito por Nietzsche como una experiencia de desasimiento. En el Prólogo de 1886 a Humano, demasiado humano leemos como el espíritu de ruptura dice: "[...] "Antes morir que vivir aquî", así resuenan la voz y

${ }^{12}$ JGB «Zweites hauptstück: der freie Geist», \$29, pp. 47-48 (MBM ed. A. Sánchez Pascual, Madrid: Alianza, 1997, p. 54).

${ }^{13}$ Cf. JGB $\$ 40$, pp. 57-58. Para una análisis de la importancia de la soledad en el tratamiento del espíritu libre ver Berkowitz, P., Nietzsche la ética de un inmoralista, tr. M. Condor, Madrid: Cátedra, 2000, pp. 290-298, y Burnett, H, «Humano, demasiado humano, livro 1. Nice, primavera de 1886", Cadernos Nietzsche, 8 (2000), 55-88.

${ }^{14}$ Cf. KSA VIII 310: 17[85]. «En conclusión: los librepensadores son los dioses de la vida liviana» $\mathrm{HH}$ II, p. 290.

${ }^{15}$ KSA VIII 462: 23[157] (HH I, p. 411). 
la seducción perentorias: ¡y este "aquí", este "en casa" es todo lo que hasta entonces había amado! Un repentino horror y deseo hacia lo que amaba, un relámpago de desprecio para lo que para ella significaba "deber", un afán turbulento, arbitrario, impetuoso como un volcán, de peregrinación, de exilio, de extrañamiento, de enfriamiento, de desintoxicación, de congelación, un odio hacia el amor, quizá un paso y una mirada sacrílegos hacia atrás $[\ldots]^{16}$. Esta es la historia del "gran desasimiento», de la liberación del espíritu que se atrever a dejar «su casa», del aventurarse al peligroso peregrinar por lo extrańo. El espíritu libre se embarca en la destrucción de su "aquí», este refugio o sitio seguro de la tradición que aporta una perspectiva consolidada y sedimentada históricamente.

Todo desasido rompe con su antiguo «deber ${ }^{17} \mathrm{y}$ despedaza su pasado. El primer paso hacia su libertad lo constituye, entonces, este martillar todo refugio, toda moral, metafísica, religión o pensamiento dogmático. Es un estar fuera de sí, de ese "aquí» que le proporciona la tradición heredada. Hay que pensar en una voluntad de separación, sin la cual no es posible la liberación. El espíritu libre es un exiliado de todo «lugar»o ámbito de significaciones instituidas, y por eso puede emprender el viaje por el laberinto del Minotauro, sin un hilo de Ariadna que lo guíe en su extravío. En un primer momento, la liberación se presenta en términos puramente negativos. Es un abandonar la casa segura para partir sin rumbo o guía a lugares desconocidos ${ }^{18}$.

Un exilio, un desquicio. Es en esta fractura de la identidad constituida por la tradición, donde se abre el espacio a la posibilidad de una nueva experiencia: la del nomadismo espiritual. Cual caminante sin rumbo y lejos de la «universal y verde felicidad-prado del rebańo, llena de seguridad, libre de peligro ${ }^{19}$, el espíritu libre se lanza a la infinidad de posibilidades que implica su libre volar. Así el operar crítico propio del espíritu libre, en su

${ }^{16}$ MA I, «Vorrede» $\$ 3$, p. 16 (HH I, p. 37).

${ }^{17}$ Cabe destacar que la crítica más acérrima en la que se embarca el espíritu libre tiene por objetivo la moral. De hecho, el interrogante más peligroso que lo guía es la siguiente pregunta: “¿No es posible subvertir todos los valores?». A pesar de ello, esta crítica puede hacerse extensiva a todo pensamiento metafísico-dogmático e interpretación del mundo que, desde la lectura nietzscheana por los efectos, siempre encierra un "deber ser», un principio que funciona como articulador de la moral.

${ }^{18}$ Retomamos aquí la caracterización de Massimo Desiato quien describe la experiencia del gran desasimiento en términos de una separación. El autor sostiene que «de la separación se produce la liberación. Al principio esta liberación es puramente negativa: "Fuera de aquî", esa es su meta. No sabemos adónde se dirige ni, de momento, importa [...]» Nietzsche, crítico de la postmodernidad, Caracas: Monte Ávila editores latinoamericanos, 1998, p. 101.

${ }^{19}$ JGB $\$ 44$, p. 61 (MBM p. 68). 
negación de lo pasado, nos abre a la perspectiva de la libre experimentación. Sin un «aquí» al que aferrarse, el pensador libre puede alzar vuelo por caminos nuevo ${ }^{20}$. Recordemos las palabras de Nietzsche en Aurora, \$501, a propósito de esta libertad conquistada: «[...] Nosotros hemos reconquistado el valor de equivocarnos, de ensayar, de adoptar conclusiones provisionales - todo lo cual tiene ya menos importancia - [...] ¡ Tenemos el derecho a experimentar con nosotros mismos! ${ }^{21}$

El espíritu libre ha conquistado, entonces, el derecho a la experimentación. Con su crítica se ha desligado de las ataduras que supone todo intento de petrificar una tradición y ha ganado para sí la libertad de equivocarse, e incluso de extraviarse ${ }^{22}$. Pero con esta posibilidad conquistada, ganada por ese primer salto al abismo en el que el espíritu libre se lanza al laberinto sin ninguna guía, se conquista también la posibilidad de emprender caminos tentativos; es decir, de encontrar algún hilo que conduzca provisoriamente nuestro viaje. La libertad de equivocarse es aquella que abre a la posibilidad de nuevas interpretaciones, a la creación de nuevos sentidos.

\section{Crítica y Olvido}

La potencia crítica se presenta como una fuerza de desprendimiento de lo pasado y de lo presente, de esos sentidos e interpretaciones petrificados, que caracteriza a la ligera libertad del espíritu. Y es este aspecto deconstructivo el que nos permite pensar la relación entre el espíritu libre y la fuerza del olvido.

El tratamiento nietzscheano más sistemático en torno a la cuestión del olvido lo encontramos en su segunda Consideración intempestiva, y en $\mathrm{La}$ genealogía de la moral, particularmente en el "Tratado segundo: "Culpa", "mala conciencia" y similares". En La genealogía de la moral, la capacidad de olvido es entendida como una fuerza, y no como «una mera vis inertiae, como creen los superficiales, sino, más bien, [como] una activa, positiva en el sentido más riguroso del término, facultad de inhibición, a la cual hay que

\footnotetext{
${ }^{20}$ Cabe señalar que son múltiples los peligros con los que se enfrenta un espíritu nómada, de los que el mayor es construir una casa aún más segura para sí. Recordemos las palabras que Zaratustra le dirige a su sombra: «Tu peligro no es pequeńo, ¡tú espíritu libre y viajero! Has tenido un mal día: ¡procura que no te toque un atardecer peor aún! / A los errantes como tú, incluso una cárcel acaba pareciéndoles la bienaventuranza - [...] / ¡Ten cuidado de no caer, al final, prisionero de una fe más estrecha todavía, de una ilusión dura y rigurosa! [...]» Za «Der Schatten», p. 341 (Za p. 367).

${ }^{21}$ M \$501, p. 294 (A tr. G. Cano, Madrid: Biblioteca Nueva, 2000, pp. 499-500).

${ }^{22}$ Es este peligroso deambular, característico del espíritu libre, el que abre al perspectivismo que constituye «la condición fundamental de toda vida». Cf. JGB pp. 11-13.
} 
atribuir el que lo únicamente vivido, experimentado por nosotros, lo asumido en nosotros, penetre en nuestra consciencia, en el estado de digestión $»^{23}$. A semejanza de lo dicho en las Consideraciones Intempestivas en las que el sentido ahistórico es entendido como la capacidad de no estar atado al instante y de desprenderse de lo pasado necesaria para la vida ${ }^{24}$, en el texto de 1887 el olvido también constituye una forma de la salud vigorosa, es ese "poco de silencio", de "tabula rasa» de la consciencia que da «sitio para lo nuevo, y sobre todo para las funciones y funcionarios más nobles» ${ }^{25}$.

El olvido aparece caracterizado por Nietzsche como una atmósfera disolutiva, un pasajero aniquilamiento que crea el "poco de silencio» para abrir sitio para lo nuevo. Sin ese "poco de tabula rasa» que constituye el olvido no existe la posibilidad de la novedad, de la aventura para experiencias nuevas, del extravío. Así la potencia crítica del espíritu libre, entendida como esa capacidad de quiebre respecto de las significaciones y vivencias ya dadas, supone la potencia del olvido. El vuelo tormentoso del espíritu liviano, el desprendimiento de la tradición, y el abandono de la casa segura, implican la potencia de desprendimiento, aniquilación y liberación de lo pasado. El despegue de la tradición, ese desasimiento al que se enfrentan los espíritus libres, sólo es posible por la fuerza del olvido. Desde esta perspectiva, el sentido ahistórico o facultad de olvido, pueden ser entendidos en términos de la capacidad de independencia propia del espíritu libre. Aquel que puede liberarse del pasado y las interpretaciones ya dadas es aquel que es capaz de olvidar. Para embarcarse en el camino de la experimentación, para reconquistar el derecho al error, es necesario poder olvidar. Aquí nos encontramos con el espíritu de ruptura, «el espíritu libre, el enemigo de las cadenas, el que no adora ${ }^{26}$, el que olvida. De este modo, vemos como la crítica y el olvido se enlazan en este espacio de liberación que rompe con los sentidos creados y petrificados históricamente.

La ligereza propia de la liberación del espíritu es posible porque existe el olvido como una fuerza que nos permite adquirir cierta independencia respecto del pasado y el presente en pos de futuras nuevas interpretaciones. Resuenan aquí las palabras del nómada de Asi habló Zaratustra: «Ajenos me son, y una burla, los hombres del presente, hacia quienes no hace mucho me empujaba el corazón; y desterrado estoy del país de mis padres y de mis

${ }^{23}$ GM II \$1, p. 291 (GM ed. A. Sánchez Pascual, Madrid: Alianza, 1997, p. 65).

${ }^{24}$ Cf. HL $\$ 1$, KSA I 248-257.

${ }^{25}$ GM p. 291 (GM p. 66)

${ }^{26} \mathrm{Za}$ «Von den berühmten Weisen», p. 132 (Za p. 155). 
madres./ Por eso amo yo tan sólo el país de mis hijos, el no descubierto, en el mar remoto: que lo busquen incesantemente ordeno ya a mis velas. ${ }^{27}$. El espíritu liviano, el nómada espiritual que se rehúsa a tener una única casa, es un espíritu que camina hacia el futuro ${ }^{28}$. Desterrado de la patria de sus padres y de sus madres, de la tierra del pasado, es posible adentrarse en el mar remoto ${ }^{29}$. Es ante este «mar abierto» que ha de estremecerse el espíritu libre, «con asombro, presentimiento y expectación $»^{30}$. La orfandad espiritual es el vínculo con el futuro, con la patria de los hijos que todavía no existen, es decir, con esa topología simbólica de la pura potencialidad. Si hemos de decir «no» a este ahora y al tiempo pasado, ha de ser en función de un futuro, futuro que en tanto tal es incierto, abierto. Por eso ordena Zaratustra a los proscritos del país de los antepasados, amar el país de los hijos, «iel país no descubierto, situado en el mar más remoto! ${ }^{31}$. Amor al futuro parece ser aquí la consigna: si hemos de olvidar, ha de ser en pos del futuro. $\mathrm{Y}$ es por este motivo por el que los espíritus libres son llamados también "los venideros" y los "pronosticadores del tiempo por venir»"

Los espíritus livianos representan la fuerza necesaria que impulsa hacia el futuro. El olvido, sin el cual no hay crítica ni negación de lo pasado posible, tiene su sentido en este orientarse hacia el porvenir y la potencialidad creativa que éste implica. En este sentido, el olvido se presenta como esa dunamis a partir de la cual el pasado, el presente, y el futuro se entrelazan.

${ }^{27} \mathrm{Za}$ «Vom Lande der Bildung», p. 155 (Za pp. 179-180).

${ }^{28}$ Cf. MA II $\$ 638$, KSA II 362-362. Ver Desiato, M., op. cit., 1998, p. 101: «El espíritu libre es el hombre que le apuesta al futuro, en contra del pasado, es el hombre intuitivo contrapuesto al racional que sólo sabe trabajar dentro de las celdillas de la tradición». Los espíritus libres, entonces, "los hombres del cambio» y del experimento.

${ }^{29} \mathrm{Cf}$. FW \$344. «De hecho nosotros, filósofos y “espíritus libres”, ante la noticia de que el "viejo Dios ha muerto", nos sentimos iluminados por una nueva aurora; ante eso nuestro corazón reboza de agradecimiento, asombro, presentimiento, expectación - finalmente el horizonte se nos aparece libre de nuevo, aun cuando no esté despejado; finalmente podrán zarpar de nuevo nuestros barcos, zarpar hacia cualquier peligro, de nuevo se permite cualquier riesgo de los que conocen; el mar, nuestro mar, yace abierto allí de nuevo, tal vez nunca hubo antes un "mar tan abierto"” GC tr. J. Jara, Caracas: Monte Ávila, 1999, p. 204.

${ }^{30}$ Como se ha podido observar, la relación entre la figura del espíritu libre y la del viajero, de aquel que se lanza al camino de la aventura y que se adentra en mares desconocidos, es relevante en el planteo nietzscheano. Cf. WS, KSA II 703-704. Ver a este respecto Quesada, J., «Tragedia y espíritu mediterráneo en F. Nietzsche: De las cuatro transformaciones del espíritu" en Actualidad de Nietzsche en el 150 aniversario de su nacimiento. Philosophica Malacitana, Suplemento 2 (1994), 97-114.

${ }^{31} \mathrm{Za}$ III «Von alten und neuen Tafeln», p. 225 (Za p. 282).

${ }^{32}$ Cf. MA II $\$ 330$, p. 515. 


\section{OlVIDO Y CREACIÓN}

El espíritu libre nos ha permitido pensar de manera conjunta la crítica y el olvido. Este espíritu independiente posee la libertad de aflojar las cadenas a las que tan insistentemente se aferran los hombres amantes de la seguridad. Y esta libertad de es el primer rasgo que hemos analizado en torno a la figura del espíritu libre, su operar destructor, su abandonar la casa segura, su gran desasimiento. Sin embargo, ya lo advierte Zaratustra, lo más importante es la libertad para, libertad que gana el desasido una vez que abandona la patria de los antepasados y zarpa en busca de la tierra de sus hijos ${ }^{33}$. "iLibre de qué? ¡Qué importa eso a Zaratustra! Tus ojos deben anunciarme con claridad: ¿libre para qué? ${ }^{34}$.

Libertad para, eso es lo que anuncia el revoloteo turbulento del ángel tormentoso. Y ¿libre para qué? ¿Para qué todos esos dolores, soledades, esa enfermedad que atraviesa el espíritu que abandona la patria de sus madres y de sus padres? ¿Para qué la libertad de dejar la red de seguridad que implica sujetarse a una tradición ya constituida? El propio Zaratustra responde a nuestras preguntas: libertad para crear. "Crear - esa es la gran redención del sufrimiento, así es como se vuelve ligera la vida. Mas para que el creador exista son necesarios sufrimiento y muchas transformaciones ${ }^{35}$. Sin la experiencia del gran desasimiento, sin los dolores y soledades, sin la enfermedad a la que se enfrenta un espíritu que se vuelve libre, no puede haber libertad para crear. Son dolores de parto lo que experimenta el desasido. Hay que ser ligero para poder ser creador. Sólo los $«$ sin casa ${ }^{36}$, los hijos del futuro ${ }^{37}$,

${ }^{33}$ La distinción entre una «libertad de» y una "libertad para» es tematizada por Barrenechea en términos de un «libertad negativa» y una "libertad positiva». Cf. Barrenechea, M., Nietzsche e a liberdade, Rio de Janeiro: 7 Letras, 2000. La distinción entre un sentido afirmativo y negativo de la libertad también es tematizada por Fink, E., La filosofía de Nietzsche, tr. A. Sánchez Pascual, Madrid: Alianza, 1996, «El superhombre y la muerte de Dios», pp. 79-88.

${ }^{34} \mathrm{Za} \mathrm{I}$ «Vom Wege des Schaffenden», p. 81 (Za p. 102).

${ }^{35} \mathrm{Za} \mathrm{II} \mathrm{«Auf} \mathrm{den} \mathrm{glückselingen} \mathrm{Inseln»,} \mathrm{p.} 110$ (Za p. 133).

${ }^{36} \mathrm{La}$ expresión utilizada por Nietzsche es Heimatlos. Heimat procede de Heim: hogar, casa, residencia. Los "sin casa" pueden ser interpretados como estos espíritus libres que deciden abandonar la propia casa. Este es el matiz que queremos subrayar al elegir esta traducción de Heimatlos. En la traducción del parágrafo de La ciencia jovial al que nos referimos, José Jara opta por traducir Heimatlos por «sin patria», elección que también nos permite aludir a la idea que hemos venido trabajando de los espíritus proscritos de la patria de sus padres y de sus madres.

${ }^{37}$ «[...] Nosotros los hijos del futuro, ¡cómo seríamos capaces de estar en este hoy como en nuestra casa! Nos desagradan todos los ideales ante los que alguien todavía podría sentirse 
aquellos que han reconquistado el derecho a equivocarse y a experimentar, podrán ser creadores.

De este modo el aspecto crítico, la posibilidad de desprendernos de los sentidos e interpretaciones heredadas, abre el espacio para la creación. Tras el abandono de toda "casa", de todo pensar unilateral asegurador, la vida se revela en todos sus matices y posibilidades ${ }^{38}$. $Y$ es por ello que ahora es necesario crear. En esta posibilidad radica el valor de la crítica, y también del olvido. "Cuando ejercemos la crítica no es nada arbitrario e impersonal- es, por lo menos muy a menudo, la prueba de que en nosotros hay allí fuerzas vivas e impulsoras que expulsan una corteza. Negamos y tenemos que negar, porque algo quiere vivir y afirmarse en nosotros, jalgo que nosotros tal vez no conocemos aún, no vemos aún!. Esto sea dicho a favor de la crítica.» ${ }^{39}$ La crítica puede revelar, entonces, las fuerzas vivas e impulsoras propias de un espíritu que dice "sí». En este sentido responde a un aspecto afirmativo del que quiere la vida. Lo que entonces aún queda por ser aclarado es la posibilidad de pensar al espíritu libre no sólo en términos de un figura de tránsito que con su operar crítico implica el perspectivismo ${ }^{40}$, sino también como una metáfora que contiene, al menos en germen, un aspecto creativo y no meramente deconstructivo. La pregunta es si en la figura del espíritu libre se conjugan la "libertad de» rechazar y destruir, con la «libertad para» experimentar y crear.

Lo que intentaremos rescatar ahora en la figura del espíritu libre, más allá de su aspecto crítico, es esta capacidad creativa propia del querer afirmativo ${ }^{41}$.

como en su casa [...] No "conservamos" nada, tampoco queremos regresar a ningún pasado [...]» FW \$377, KSA III 628-629 (GC p. 247).

${ }^{38} \mathrm{La}$ idea del perspectivismo puede entenderse en este contexto como la posibilidad que conquista el espíritu de deambular, de viajar por nuevos caminos, de acceder a un mundo de matices y múltiples puntos de vista. Para la relación entre el perspectivismo y la temática de la subjetividad cf. Parmeggiani, M., Perspectivismo y subjetividad en Nietzsche, Málaga: Analecta Malacitana, 2002.

${ }^{39} \mathrm{FW} \$ 307$, p. 545 (GC p. 179).

${ }^{40}$ Ésta es, entre otros, la interpretación que nos propone Julio Quesada en su libro Un pensamiento intempestivo. Ontología, estética y politica en F. Nietzsche, Barcelona: Anthropos, 1988. Cf. «Epílogo. El eterno retorno como finalidad sin fin (Nietzsche y Kant)», pp. 371378.

${ }^{41}$ En esta línea interpretativa se encuentra la propuesta de Desiato a la que ya hemos aludido. Si bien su enfoque parte desde un análisis de la cultura que busca elucidar la relación entre el individuo y la comunidad, la figura del espíritu libre también aparece descripta en términos afirmativos. "La superación de la tradición cultural no puede acontecer sin la creación de otra moral: el espíritu libre no es sólo aquel que destruye la moral objetiva: es también y sobre todo el hombre capaz de generar nuevos valores y una nueva cultura» Desiato, 
Para ello estimamos útil recurrir al capítulo «De las tres transformaciones» de Así habló Zaratustra. Allí Nietzsche menciona tres transformaciones del espíritu: la del espíritu en camello, la del camello en león, y la del león en nińo. Si atendemos al aspecto crítico que representa el espíritu libre, y en el que tanto énfasis hace Nietzsche, esta figura parece representar al león. De hecho, es el león el que "quiere conquistar su libertad como se conquista una presa», y se enfrenta para convertirse en seńor de su propio desierto ante el gran dragón que es el «Tú debes», los valores milenarios. El gran dragón es quien dice: "Todos los valores han ya sido creados, y yo soy-todos los valores creados» ${ }^{42}$.

El león es el que combate a este gran dragón, pues es necesario crear valores nuevos, pero «tampoco el león es aún capaz de hacerlo» pues sólo puede "crearse la libertad para un nuevo crear»" ${ }^{43}$. Si bien es verdad que el espíritu libre, al igual que león, crea las condiciones que posibilitan un nuevo crear- pues es él quien destruye el "aquí», la "casa» segura, y nos abre a la posibilidad del perspectivismo ${ }^{44}$, de los matices-, aún queda por determinarse si el espíritu libre, al igual que el león, es incapaz de crear nuevos valores.

En el prefacio a Humano, demasiado humano, Nietzsche describe el aislamiento enfermizo que debe atravesar el espíritu libre como parte del recorrido que le permite llegar a esa "libertad madura del espíritu» que posibilita el acceso a muchos y contrapuestos modos de pensar. Ese peligro de perderse y quedarse sentado en cualquier rincón es parte del proceso curativo que lleva a la "gran salud» ${ }^{45}$, a «ese exceso de fuerzas plásticas, curativas,

M., op. cit., p. 131. Cf. Nehamas, A., Nietzsche. Life as Literature, Harvard University Press, 1996, cap. II: "Untruth as a condition for like», pp. 42-73.

${ }^{42} \mathrm{Za} \mathrm{I}$ «Von der drei Verwandlungen», p. 30 (Za p. 50).

${ }^{43}$ Ibid.

${ }^{44}$ Cf. Cragnolini, M., Nietzsche, camino y demora, Buenos Aires: Eudeba, 1998, cap. III: «Nihilismo integral: la filosofía del martillo», nota 7, p. 87: "Así el camello (el hombre decadente) se transforma en león (espíritu libre) en el desierto [...]». Fink, F., op. cit., p. 85: «[La figura de] el espíritu libre, el hombre crítico y negador, el marinero audaz que navega hacia costas desconocidas y lejanas, corresponde al león".

${ }^{45}$ Parmeggiani describe esta "gran salud» en oposición a la salud del hombre del rebańo. "La salud del último hombre funciona con el principio de conservación (del individuo y de la colectividad), mientras que la gran salud funciona con el principio de autosuperación, contenido en la dimensión de la Versuch. El ensayo y el experimento desplazan la vida incesantemente a sus últimos límites, a sus umbrales» Parmeggiani, M., op. cit., p. 21. Para un análisis de la relación entre el perspectivismo y la salud cf. Vieira, Amorin, $O$ desafio da grande saúde em Nietzsche, Rio de Janeiro: 7 Letras, 2000. Aquí se desarrolla el concepto de «salud mutable» (Saúde mutável). Siguiendo esta línea interpretativa, ver también Long, T., «Nietzsche's Philosophy of Medicine», Nietzsche-Studien, 19 (1990), 112-128. 
reproductoras, [...] ese exceso que le da al espíritu el peligroso privilegio de poder vivir en la tentativa y ofrecerse a la aventura: ¡el privilegio de maestría del espíritu libre! ${ }^{46}$. En la gran salud, en este privilegio del espíritu libre, parece estar la clave para comprender el aspecto creativo del que es capaz el espíritu liviano.

La gran salud a la que puede acceder el espíritu libre luego de largos ańos de convalecencia, enfermedad y sufrimiento, se caracteriza por un exceso de fuerzas plásticas, curativas, reproductoras y restauradoras. Esta fuerza plástica había sido analizada ya por Nietzsche en relación al olvido en sus segunda Consideración intempestiva, y descrito como esa "[...] fuerza capaz de crecer originalmente a partir de sí misma, de transformar lo pasado y lo extraño, de curar heridas, de reemplazar lo perdido, de configurar de nuevo las formas quebradas. ${ }^{47}$. El signo de la gran salud del espíritu libre radica en esta plasticidad que no se limita a negar lo pasado, o olvidar los sentidos creados, sino que es también potencia creativa - potencia capaz no sólo de olvidar lo pasado, sino también de transformarlo, de configurar formas nuevas para reemplazar lo perdido. La fuerza plástica parece adecuarse a lo dicho a favor de la crítica por Nietzsche en Aurora. Negamos porque algo quiere afirmarse en nosotros. Olvidamos porque algo dice sí en nosotros, aún cuando todavía no sepamos qué. Olvidamos para poder crear.

Es importante destacar que la fuerza e importancia de la crítica, de la negación y del olvido, propios del espíritu libre, radican en esta posibilidad abierta por ellos para la creación de nuevos sentidos, de reemplazo de lo perdido y transformación de lo pasado y extraño. De hecho, «El librepensador vive para el futuro del hombre, inventando nuevas posibilidades de vida y ponderando las antiguas. ${ }^{48}$. Los espíritus libres no sólo son los que rasgan los hilos de la tradición sino también aquellos que descubren e inventan nuevos caminos, posibilidades y perspectivas para la vida. Este aspecto afirmativo, que constituye la potencialidad creativa, incluye y supone la posibilidad de recrear los sentidos ya dados. De hecho, la capacidad crítica no está reńida con la posibilidad de ponderar y transformar lo pasado. Nietzsche sostiene que no siempre es necesario desembarazarse de las hipótesis más antiguas y venerables dado que éstas pueden abrir el camino a nuevas formulaciones

Allí nos propone pensar la salud nietzscheana en términos «perspectivísticos» («health is perspectival»).

${ }^{46} \mathrm{Za}$ «Vorrede» \$4, p. 18 (Za p. 38).

${ }^{47} \mathrm{HL} \$ 1$, p. 251 (UPH tr. O. Caeiro, Buenos Aires: Alción Editora, 1998, p. 32).

${ }^{48}$ KSA VIII 308: 17[44] (HH I p. 285). 
y refinamientos ${ }^{49}$. De manera que la crítica, el olvido y la creación no están reñidos con la posibilidad de la transformación de lo pasado. Los sentidos, hipótesis, e interpretaciones de la tradición pueden ser reconfiguradas, reformuladas, es decir, recreadas ${ }^{50}$. La capacidad creativa de la fuerza plástica ha de ser entendida, entonces, como potencialidad recreativa. El límite para el olvido y para la crítica es el mismo: la fuerza que es signo de la gran salud. Y será sólo en la tensión entre el aniquilamiento y la conservación, entre la capacidad del olvido y la memoria, entre el sentir ahistórico e histórico, donde la fuerza plástica puede crear y reemplazar lo perdido.

En la fuerza plástica se conjugan la libertad de y la libertad para, constituyendo el espacio propicio para pensar de modo conjunto la afirmación y la negación, la crítica y la creación, y olvido y la conservación de lo pasado. Estos aspectos negativo y afirmativo se entrelazan a partir de la idea de una potencia re-creativa en la que el olvido actúa como la fuerza que permite el movimiento de oscilación que se desplaza desde el pasado hacia el futuro, desde la destrucción hacia la construcción.

\section{El baile encadenado}

El olvido representa, entonces, el límite para el desarrollo de la fuerza plástica. Fuerza ésta que hemos entendido en términos de un potencia re-creativa en la que es posible una transformación de lo pasado en pos de nuevas interpretaciones y modos de vida. La libertad de espíritu se conecta así con la posibilidad de reformular los sentidos dados recreando perspectivas novedosas. Un modo de pensar esta fuerza plástica propia de los espíritus libres sea en términos de lo que Nietzsche llamó en alusión a Voltaire el «baile encadenado», donde la fuerza creativa se muestra en la potencia de flexibilizar las interpretaciones y sentidos dados.

Una libertad encadenada es lo que revela Homero en el que "puede percibirse una plétora de fórmulas heredadas y leyes narrativas épicas, dentro de las cuales debía bailar; y él mismo añadió la creación de nuevas convenciones para los venideros. ${ }^{51}$ Este bailar encadenado es el baile propio

${ }^{49}$ Cf. JGB $\$ 12$, pp. 26-27. Esto lo propone Nietzsche respecto de la hipótesis sobre el alma.

${ }^{50}$ Cf. Nehamas, A., op. cit., p. 97: «But in Nietzsche's own view, reinterpretation is the most poweful theoretical and practical instrument. It is the literal analogue of "the hammer" with which he proposes to do philosophy in the Preface of The Twilight of the Idols; part tuning fork to sound out hollow idols, part instrument of their destruction, and part sculpturor's mallet to fashion new statues out of the forms as well as the materials of the old».

${ }^{51}$ MA II $\$ 140$, p. 612 (HH II pp. 162-163). Cf. MA II \$159, p. 618. 
de la re-creación, que se desarrolla «[...] jugando y bailando como el espíritu más libre y gracioso dentro de estas trabas $[\ldots]]^{52}$. 'Resignificar', transformar y reconfigurar implican flexibilizar las cadenas que intentan estrechar el espíritu en el marco rígido y monótono de la mismidad ${ }^{53}$. Recordemos la «facilidad y ligereza de la fantasía homérica» que con su "placer de fabular» pudo transformar y recrear a sus dioses ${ }^{54}$. Esta liviandad homérica es la misma que caracteriza al espíritu libre como hombre del futuro. La libertad espiritual no puede comprenderse meramente como una ruptura de las cadenas del presente y del pasado, sino que implica de una liberación en el interior de las propias cadenas para así permitir el aflorar de nuevos sentidos e interpretaciones ${ }^{55}$. La ligereza es, en este sentido, la flexibilidad que comporta la fuerza plástica y recreativa, una danza entre los sentidos del pasado, del presente y del futuro.

Los espíritus libres poseen la grandeza espiritual propia de aquellos que han sabido sembrar en las antiguas hipótesis para cosechar nuevas posibilidades de vida. "Todos los grandes han sido grandes trabajadores, infatigables no sólo en el inventar, sino también en el desechar, tamizar, modificar, ordenar ${ }^{56}$. Es esta invención que implica una modificación y ordenamiento de lo precedente, un arduo proceso de reconfiguración y resignificación, a lo que alude la fuerza plástica y recreativa que caracteriza a la ligereza del espíritu de los venideros. Los filósofos del futuro han de ser espíritus libres porque han de ser críticos, experimentadores y creadores como ellos ${ }^{57}$. Ellos también han de ser dioses de la vida liviana.

${ }^{52}$ Ibid. p. 618 (ibid. p. 159).

${ }^{53}$ Para una análisis de los caracteres de flexibilidad y complejidad del espíritu libre cf. Reginster, B., "What is a Free Spirit? Nietzsche on fanaticism", Archiv für Geschichte der Philosophie, 85 (2003), 51-83.

${ }^{54}$ Cf. KSA VIII 72: 5[121] y KSA VIII 203-204: 11[18].

${ }_{55}$ Para un análisis de la relación entre Homero y el espíritu libre cf. Ponton, O., «Les esprits libres sont les "dieux à la vie facile"», en D'Iorio, P. y Ponton, O. (eds), op. cit., p. 180: "l'allégement ne consiste pas à se libérer de ses liens, mais à se libérer 'dans les liens'». "Ainsi, le lien léger qui relie l'esprit libre à l'action s'apparente à l'irréligiosité du poète: une même légèreté s'exprime dans la contemplation de l'esprit libre, qui n'est pas l'esclave de ses actes mais qui imagine différentes possibilités de vie, et dans la "libre poétisation" d'Homère, qui n'est pas l'esclave de ses dieux mas se sent libre à leur égard et les façonne à sa guise» pp. 181-182.

${ }^{56}$ MA I $\$ 155$, p. 123 (HH I p. 123).

${ }^{57}$ Cf. JGB $\$ \$ 39-44$ y $\$ \$ 210-213$, pp. 56-63 y 142-149. 